\title{
FUNCTIONAL INTEGRITY AND AGING OF THE LEFT INTERNAL THORACIC ARTERY AFTER CORONARY ARTERY BYPASS SURGERY
}

Giovanni Amoroso, $\mathrm{MD}^{\mathrm{a}}$

René A. Tio, MD, $\mathrm{PhD}^{\mathrm{a}}$

Massimo A. Mariani, $\mathrm{MD}, \mathrm{PhD}^{\mathrm{b}}$

Adrianus J. van Boven, $\mathrm{MD}, \mathrm{PhD}^{\mathrm{a}}$

Gillian A. J. Jessurun, MD, $\mathrm{PhD}^{\mathrm{a}}$

Stefan H. J. Monnink, MD, $\mathrm{PhD}^{\mathrm{a}}$

Jan G. Grandjean, MD, $\mathrm{PhD}^{\mathrm{b}}$

Piet W. Boonstra, $\mathrm{MD}, \mathrm{PhD}^{\mathrm{b}}$

Harry J. G. M. Crijns, MD, PhD
Objective: To study the endothelial function in the left internal thoracic artery after coronary artery bypass surgery and to identify predictors of early dysfunction, we performed a provocative test with acetylcholine in 23 male patients who underwent routine postoperative coronary angiography.

Methods: The change in mean diameter of the proximal thoracic artery was assessed by quantitative angiography after selective injections of acetylcholine and nitroglycerin.

Results: The thoracic artery showed a $6.8 \%(P<.001)$ and $9.0 \%(P<.001)$ increase in mean diameter after acetylcholine and nitroglycerin administration, respectively. Vasodilative responses to acetylcholine and nitroglycerin administration were strongly correlated $(R: 0.88 ; P<.001)$. Among the common risk factors, only age was associated with an impairment in the vasodilative response of the arterial graft $(P=.001)$, and acetylcholineinduced vasodilation was inversely correlated to the age of the patient (R: $0.69 ; P<.001)$.

Conclusions: Endothelium-dependent vasodilative response to acetylcholine administration seems well preserved in the left internal thoracic artery after surgery. Common risk factors, except for age, do not affect the functional integrity of the arterial graft. The vasodilative properties of the graft depend on the age of the patient and do not deteriorate over time after operation. (J Thorac Cardiovasc Surg 2000;120:313-8)
$T^{1}$ he left internal thoracic artery (LITA) shows an excellent long-term angiographic patency after coronary artery bypass grafting $(\mathrm{CABG})^{1,2}$; this entails good long-term results in terms of cardiac event-free survival. $^{3,4}$ The normal biologic properties of the endothelium can guard the grafted LITA from thrombus formation and vasospasm. ${ }^{5}$ Acetylcholine, an endothelium-dependent vasodilative mediator, is able to detect

From the Department of Cardiology and Department of Cardiothoracic Surgery, ${ }^{\mathrm{b}}$ Thoraxcenter, University Hospital of Groningen, The Netherlands.

René A. Tio received financial support from The Netherlands Heart Foundation, grant D95-019.

Received for publication Oct 20, 1999; revisions requested Dec 22, 1999; revisions received Feb 7, 2000; accepted for publication Feb 28, 2000.

Address for reprints: Giovanni Amoroso, MD, Thoraxcentrum, University Hospital Groningen, PO Box 30 001, 9700 RB Groningen, The Netherlands

(E-mail: G.Amoroso@thorax.azg.nl).

Copyright () 2000 by The American Association for Thoracic Surgery

$0022-5223 / 2000 \$ 12.00+0 \quad \mathbf{1 2 / 1 / 1 0 6 8 3 9}$

doi: $10.1067 / \mathrm{mtc} .2000 .106839$ impairment in endothelial function when it is infused in angiographically normal arteries; the endothelial dysfunction is shown by an aberrant vasoconstrictive response that is due to the lack of release of nitric oxide by the endothelial cells. ${ }^{6}$ Endothelial dysfunction has been associated with the development of atherosclerosis. ${ }^{7}$ Any alteration in acetylcholine-induced response can be seen as a risk indicator for early atherosclerosis in the LITA after CABG, and conversely, preserved endothelial function suggests functional integrity of the LITA. ${ }^{8}$ However, there is no current agreement about the factors that could affect the functional integrity of the grafted LITA.

The aim of this study was to verify whether the endothelial function of the LITA was preserved and to identify factors that could affect its functional integrity after $\mathrm{CABG}$.

\section{Methods}

Study design. To verify whether the endothelial function of the LITA was preserved after CABG, we performed a provocative test with acetylcholine in patients who underwent routine postoperative coronary angiography. In addition, to 
Table I. Clinical features of the patients ( $n=23$ patients) and atherosclerotic risk factors

\begin{tabular}{lc}
\hline Age of patients (y) & $64.5 \pm 7.4$ \\
Age of graft at follow-up (mo) & $30.5 \pm 19.3$ \\
No. of LITAs used as a sequential graft (\%) & $7(30)$ \\
LVEF (\%) & $51.6 \pm 9.3$ \\
No. of patients receiving ACE inhibitors (\%) & $8(35)$ \\
No. of patients receiving statins (\%) & $11(48)$ \\
No. of patients with a previous history of: & \\
Hypercholesterolemia (\%) & $9(39)$ \\
Systemic hypertension (\%) & $7(30)$ \\
Diabetes mellitus (\%) & $3(13)$ \\
Smoking (\%) & $10(43)$ \\
MI in the grafted area (\%) & $6(26)$
\end{tabular}

LITA, Left internal thoracic artery; $L V E F$, left ventricular ejection fraction; $A C E$, angiotensin-converting enzyme; $M I$, myocardial infarction.

identify any possible predictor for endothelial dysfunction, we studied the association between the patients' characteristics, including risk factors for coronary artery disease, and the LITA response to vasoactive agents. The design of the study was prospective. Consecutive patients who were undergoing postoperative angiographic investigation as part of other angiographic follow-up studies were asked to enter this study when they complied with the following inclusion criteria: aged between 18 and 80 years, first coronary operation, and an uncomplicated postoperative course. Exclusion criteria were the presence of left ventricular dysfunction (ejection fraction < $40 \%$ ), atherosclerotic vascular disease involving the supra-aortic branches, renal dysfunction (blood creatinine level $\geq 2.0 \mathrm{mg} / \mathrm{dL}$ ), and unstable or progressive angina during the 3 months preceding the examination.

The study design was approved by the institutional review board, and patients gave informed consent to the study.

Patients. From January 1998 until June 1999, 23 male patients (mean age $64.5 \pm 7.4$ years) entered the study and were submitted to an angiographic follow-up investigation after CABG. The mean age of the graft at follow-up (time since operation) was $30.5 \pm 19.3$ months (range, 6-60 months). Clinical features of the patients at the time of follow-up are shown in Table I. Common risk factors, which were present at the time of operation, are also shown in Table I. Patients were identified as having hypercholesterolemia, hypertension, or diabetes, respectively, when low-density lipoprotein cholesterol level was $100 \mathrm{mg} / \mathrm{dL}$ or higher or the patient was receiving lipid-lowering medication; blood pressure level was $140 / 90 \mathrm{~mm} \mathrm{Hg}$ or higher or the patient was receiving antihypertensive medication; total glycosylated hemoglobin level was $10 \%$ or more or the patient was receiving oral glucose-lowering or insulin treatment. Those patients who smoked more than 5 cigarettes per day at the date of operation or who had quit smoking cigarettes less than 1 week before were classified as smokers. The previous occurrence of myocardial infarction in the grafted area was also assessed. No restriction was given for drug regimen, including the use of angiotensin-converting enzyme inhibitors,
angiotensin-II antagonists, and statins; all patients were receiving aspirin therapy.

Surgical technique. All patients underwent elective primary coronary operations for the treatment of multivessel coronary artery disease. Standard cardiopulmonary bypass and cardioplegic arrest were used. All LITAs were harvested as pedicled grafts from their origin at the subclavian artery down to the bifurcation, by means of electrocautery and surgical clips. ${ }^{9}$ All LITAs were anastomosed onto the left anterior descending artery system; single or sequential anastomoses were performed on a per-patient evaluation basis.

Acetylcholine test. Nitrates, calcium antagonists, and $\beta$ blockers were discontinued at least 24 hours before the acetylcholine test. The angiographic study was performed by a femoral approach; $6 \mathrm{~F}$ common diagnostic catheters and ITA or Judkins right diagnostic catheters (Cordis BV, Roden, The Netherlands) were used, respectively, for native vessels and for selective injections in the LITA. The nonionic contrast dye chosen for angiography was Iohexol (Omnipaque 350; Nycomed BV, Breda, The Netherlands). Native vessels and LITA were filmed in at least 2 orthogonal projections.

The acetylcholine test was performed after the routine angiographic investigation; a fixed radiologic projection was selected, and angiograms of the LITA were acquired as baseline references. Acetylcholine was selectively injected in the LITA, starting with 2 subsequent test dosages $\left(10^{-8}\right.$ and $10^{-7}$ $\mathrm{mmol} / \mathrm{mL}$ ); when no individual hypersensitivity to the drug was assessed, the desired effective dosage $\left(10^{-6} \mathrm{mmol} / \mathrm{mL} \times\right.$ 3 minutes) was administered, and angiograms were acquired within 1 minute after the end of the infusion. A bolus (500 $\mu \mathrm{g}$ ) of nitroglycerin was administered into the LITA (with a washout period of 5 minutes after the end of the acetylcholine infusion), and angiograms were acquired again. The electrocardiogram and systemic blood pressure were continuously monitored during the examination. Images were digitally stored for the postprocessing analysis.

Quantitative coronary angiography. All images were analyzed by means of the computerized automatic system Quantocor QCA (CAAS II) version 3.0 (Pie Medical Imaging, Maastricht, The Netherlands), which provides an intraobserver and interobserver variability for computed reference diameters of less than $10^{-1} \mathrm{~mm} .^{10}$ End-diastolic frames were chosen from each angiographic sequence for quantification analysis. Measurements were performed in the proximal LITA, where a segment, at least $3-\mathrm{cm}$ long and at least $3-\mathrm{cm}$ distal from the ostium, was selected for serial analysis; side branches, metallic clips, or other anatomic references were used to obtain fixed coordinates. A variability in the length of the selected segment of less than $10 \%$ was accepted. The tip of the catheter was used as a scaling device; an automatic contour detection was performed, and the mean diameter of the selected segment was calculated in each sequence. A mean of 3 repeated measurements was performed for any segment to minimize the error in the assessment of the vessel diameter.

Statistical analysis. All data were collected in a customized database and processed with the use of the SPSS 
8.0 for Windows statistical package (SPSS Inc, SPSS, Inc, Chicago, Ill). Descriptive statistics are expressed as mean values \pm SD or as percentages. Because acetylcholine is an endothelium-dependent vasomediator and nitroglycerin is an endothelium-independent vasomediator, they were considered as 2 different treatments, and their effects on the vasomotility of the LITA were separately analyzed. The paired Student $t$ test was performed to compare values for the mean diameter of the LITA after treatments with baseline values. To determine the predictive factors of diameters changes after treatment versus baseline, we performed univariate regression analysis with clinical features and common risk factors. Variables with a probability value of less than .20 were selected for the multivariable regression analysis to derive a model with statistically significant factors. Linear regression analysis was performed to correlate the vasodilative effects of acetylcholine and nitroglycerin administration. Linear regression analysis was also performed for any of the continuous variables that reached statistical significance.

\section{Results}

At the time of follow-up, all the patients were free of symptoms. At the angiographic examination, 23 of 23 LITAs were patent and without stenosis. Four patients did not complete the acetylcholine test for the following reasons: selective engagement of the LITA not adequately stable ( 2 patients) and individual hypersensitivity at the test dosages (chest pain or ischemic electrocardiographic changes without evident angiographic abnormalities, 2 patients).

In the remaining 19 patients, the mean diameter of the LITA increased from $2.86 \pm 0.34 \mathrm{~mm}$ at baseline to $3.05 \pm 0.38 \mathrm{~mm}(+6.8 \% ; P<.001 ; 95 \%$ confidence interval, -0.27 to -0.10$)$ after acetylcholine administration and to $3.11 \pm 0.40 \mathrm{~mm}(+9.0 \% ; P<.001 ; 95 \%$ confidence interval, -0.35 to -0.15 ) after nitroglycerin administration (Fig 1). Hemodynamics did not vary significantly during acetylcholine and nitroglycerin administration.

A strong correlation was found between vasodilation after acetylcholine and nitroglycerin administration $(R$ : $0.88 ; P<.001 ;$ Fig 2$)$

At univariate analysis, age was the only predictor of a different vasodilative response of the LITA to acetylcholine administration $(P=.001)$. None of the other clinical features and atherosclerotic risk factors showed a significant association with vasodilation after acetylcholine administration; thus, a multivariable analysis was not performed. In particular, the age of the graft was not associated with an impairment in the vasodilative response to acetylcholine administration $(P=.39)$. The individual change in diameter ver-

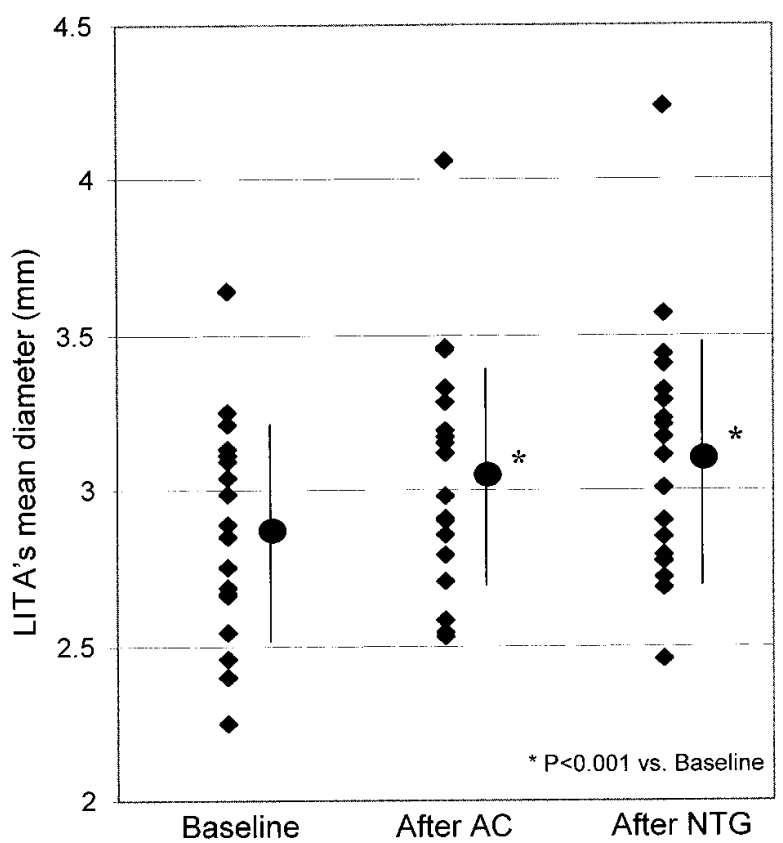

Fig 1. The mean diameter of the LITA at baseline, after acetylcholine $(A C)$ administration, and after nitroglycerin $(N T G)$ administration. Mean \pm SD for each phase is also shown. A significant increase was found after both treatments $(P<.001)$.

sus baseline and the age of the patient were inversely correlated $(R: 0.69 ; P<.001$; Fig 3$)$.

At univariate analysis, age was again the only predictor of a different vasodilative response of the LITA to nitroglycerin administration $(P=.001)$. According to univariate analysis, the type of anastomosis (single or sequential) was also associated $(P=.096)$ but, at a multivariable analysis including both these factors, only the age of the patient was found to be a significant factor $(P=.001)$ for vasodilation after nitroglycerin administration.

\section{Discussion}

This study demonstrates that, in vivo, the pedicled LITA shows a long-term functional integrity after CABG.

Several experimental studies demonstrated that isolated rings of internal thoracic arteries (ITAs) from patients who were submitted to surgical intervention show relaxation in response both to endotheliumdependent (acetylcholine, thrombin, adenosine) and to endothelium-independent mediators (sodium nitroprusside, glyceryl trinitrate); the presence of an intact endothelial layer is also able to prevent serotonininduced vasoconstriction. ${ }^{11-14}$ 


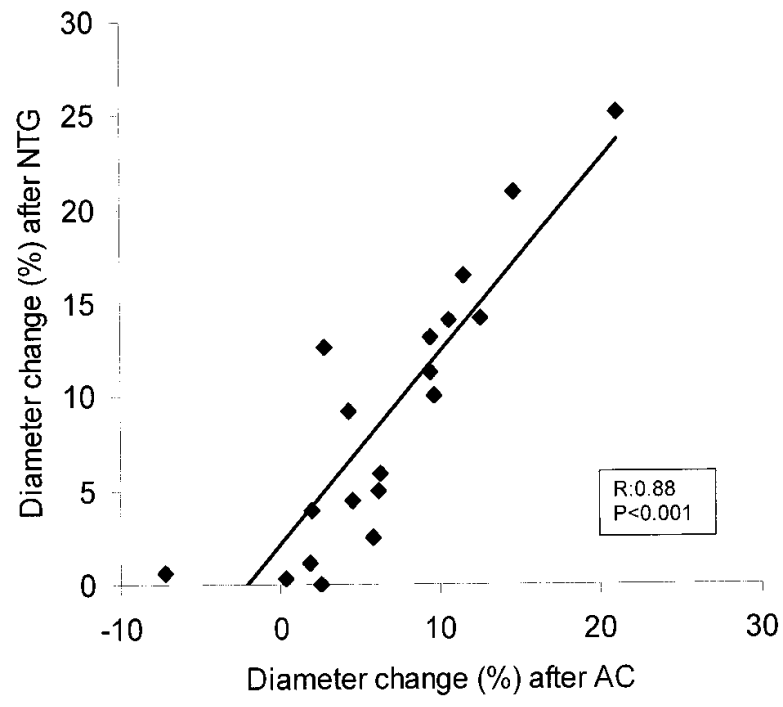

Fig 2. Correlation between vasodilation of the LITA (percent vs baseline values) after nitroglycerin $(N T G)$ and acetylcholine $(A C)$ administration. Nitroglycerin- and acetylcholine-induced vasodilation appeared significantly correlated $(P<.001)$.

In accordance with these findings, the present study shows a preserved vasomotor response of the LITA after operation, both to endothelium-dependent and to endothelium-independent stimuli.

The presence of several risk factors is known to worsen the clinical outcome of subjects with coronary artery disease..$^{15}$ Patients who undergo CABG usually have an advanced grade of atherosclerosis. Although it is reasonable to assume that ITAs may be involved in the disease process, no conclusive results were found on the influence of diffuse atherosclerosis on the normal function of the LITA. In fact, although Tanaka and colleagues ${ }^{16}$ showed that free ITAs have a normal pattern of vasomotion regardless of the extent of coronary artery disease, Berkenboom and colleagues ${ }^{17}$ found an impaired acetylcholine-induced vasomotor response in ITAs of patients with severe coronary atherosclerosis.

In our study group, LITAs appeared to be free from angiographically detectable stenosis and subclinical atherosclerosis, despite the presence of severe coronary atherosclerosis, and they showed a preserved vasodilative response, even in the presence of multiple risk factors.

In an experimental model, Voors and colleagues ${ }^{18}$ have demonstrated a relationship between endothelium-dependent relaxation in apparently nondiseased LITAs used for operation and preoperative low-density lipoprotein cholesterol levels. In our setting, hyper-

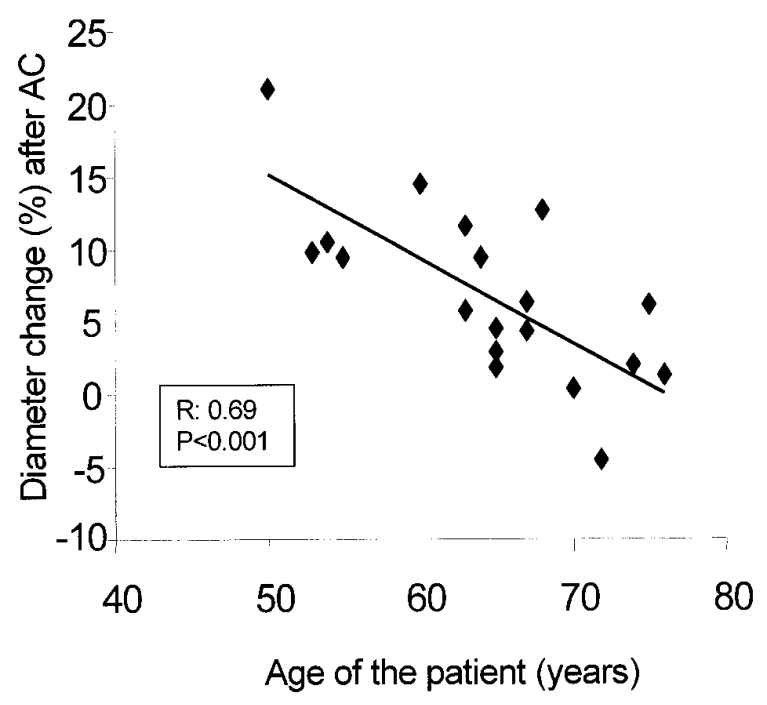

Fig 3. Correlation between vasodilation of the LITA (percent vs baseline values) after acetylcholine $(A C)$ administration and the age of the patient. The acetylcholine-induced vasodilation appeared to reduce progressively as the age increased $(P<.001)$.

cholesterolemia was not predictive for an impairment of the endothelial function of the LITA. Moreover, no abnormal response to acetylcholine administration was found in the presence of other risk factors, such as systemic hypertension, diabetes mellitus, and smoking before the operation. Therefore, these results suggest that, unlike other arterial regions, LITAs show a different and slower progression of the atherosclerotic process.

Our findings confirm the results of previous studies on the functional behavior of ITAs after CABG and allow further interpretations in a clinical prospective. In the study group of Hanet and colleagues, ${ }^{19}$ ITA grafts showed a better vasodilator reserve than vein grafts. Gurné and colleagues ${ }^{20}$ also demonstrated a vasodilative effect of nitrates and papaverine on grafted ITAs early and late after the intervention. Although all these investigations showed a preserved vasodilative response, they provided only indirect evidence about the endothelial function of ITAs after surgical intervention.

Although the use of a LITA as a pedicled graft allows the maintenance of its anatomic integrity, it alters its functional flow parameters. In fact, the LITA is a resistance conduit with mainly systolic blood flow when in situ. After operation, the LITA immediately shows the characteristics of a conductance conduit, with a prevalent diastolic flow comparable with that of the epicar- 
dial coronary arteries..$^{21}$ Any modification in flow behavior might lead to endothelial dysfunction. An additional cause for disturbed endothelial function may be related to manipulation during surgery.

After acetylcholine infusion, Werner and colleagues ${ }^{22}$ found a significant vasodilation of ITA grafts, even if vasoconstriction occurred in coronary segments distal to the anastomosis. In contrast with these results, Hartmann and colleagues ${ }^{23}$ found only a nonsignificant change in arterial graft diameter after acetylcholine and nitrate administration, despite a significant reduction of coronary resistances in the supplied area. In that study, the authors hypothesized that the longer time of followup (more than 3 years) could be responsible for the inconclusive findings and may suggest that, in the long term, the grafted ITA loses the capability to react to vasoactive stimuli.

This notion, however, is not supported by our study, in which the grafted LITAs showed a preserved vasodilative response both to endothelium-dependent and -independent mediators, despite the long period of follow-up (range, 6 months to 5 years). The functional integrity of the LITA appeared to be related only to the age of patients but not to the age of the graft at the time of the acetylcholine test. Therefore, the surgical manipulation and the subsequent alteration in flow pattern do not seem to accelerate the aging process of the LITA. Nevertheless, the fact that the vasodilative response to acetylcholine administration in each patient was closely related to the vasodilative effect of nitrates suggests that, in elderly patients, the physiologic release of endothelial nitric oxide is preserved and that only intrinsic properties of the media layer could be responsible for the variability in vasodilation.

The present study has 2 limitations. First, we did not analyze the response to acetylcholine administration of the coronary district in the area supplied by the LITA. This analysis was beyond the purpose of the study because the presence of atherosclerosis was implicit in that district. Another limitation is the small number of patients, because of the restrictive selection criteria.

In conclusion, endothelium-dependent vasodilative response to acetylcholine administration is preserved in the LITA after operation. Common risk factors, except for older age, do not affect the functional integrity of the arterial graft. The vasodilative properties of the graft depend on the age of the patient and do not deteriorate over time after operation. Our results confirm and may give an explanation for the excellent longterm clinical and angiographic outcomes of LITA grafts. The anatomic and functional characteristics of the LITA late after the operation strongly support the continued use of ITA grafts, regardless of the presence of multiple risk factors and severe atherosclerosis.

We thank Ms Paula J. Buentello for her assistance in preparing this manuscript and Nic Veeger, MSC, and Corine Volkers, MSC, for reviewing the statistical analysis.

\section{REFERENCES}

1. Boylan MJ, Lytle BW, Loop FD, Taylor PC, Borsh JA, Goormastic M, et al. Surgical treatment of isolated left anterior descending coronary stenosis: comparison of left internal mammary artery and venous autograft at 18 to 20 years of follow-up. J Thorac Cardiovasc Surg 1994;107:657-62.

2. Loop FD. Internal-thoracic-artery grafts. $\mathrm{N}$ Engl J Med 1996;334:263-5

3. Cameron A, Davis KB, Green G, Schaff HV. Coronary bypass surgery with internal-thoracic-artery grafts: effects on survival over a 15-year period. N Engl J Med 1996;334:216-9.

4. Lytle BW, Blackstone RH, Loop FD, Houghtaling PL, Arnold $\mathrm{JH}$, Akhrass R, et al. Two internal thoracic artery grafts are better than one. J Thorac Cardiovasc Surg 1999;117:855-72.

5. Lüscher TF, Diederich D, Siebenmann R, Lehmann K, Stulz P, von Seggesser L, et al. Difference between endothelium-dependent relaxation in arterial and in venous coronary bypass grafts. N Engl J Med 1988;319:462-7.

6. Ludmer PL, Selwyn AP, Shook TL, Wayne RR, Mudge GH, Alexander RW, et al. Paradoxical vasoconstriction induced by acetylcholine in atherosclerotic coronary arteries. N Engl J Med 1986;315:1046-51.

7. Lerman A, Cannan CR, Higano SH, Nishimura RA, Holmes DR Jr. Coronary vascular remodeling in association with endothelial dysfunction. Am J Cardiol 1998;81:1105-9.

8. Gibbons GH. Endothelial function as a determinant of vascular function and structure: a new therapeutic target. Am J Cardiol 1997;79:3-8.

9. Grandjean JG, Voors AA, Boonstra PW, den Heyer P, Ebels T. Exclusive use of arterial grafts in coronary artery bypass operations for three-vessel disease: use of both thoracic arteries and the gastroepiploic artery in 256 consecutive patients. J Thorac Cardiovasc Surg 1996;112:935-42.

10. Gronenschild E, Janssen J, Tijdens F. CAAS II: a second generation system for off-line and on-line quantitative coronary angiography. Cathet Cardiovasc Diagn 1994;33:61-75.

11. He GW, Acuff TE, Ryan WH, Yang CQ, Mack MJ. Functional comparison between the human inferior epigastric artery and internal mammary artery: similarities and differences. J Thorac Cardiovasc Surg 1996;109:13-20.

12. Ochiai M, Ohno M, Taguchi J, Hara K, Suma H, Isshiki T, et al. Responses of human gastroepiploic arteries to vasoactive substances: comparison with responses of internal mammary arteries and saphenous veins. J Thorac Cardiovasc Surg 1992;104:453-8.

13. Unger P, Berkenboom G, De Smet JM, Depierreux M, Fontaine $\mathrm{J}$. Influence of the endothelium on the responses to endogenous agonists in human internal mammary and gastroepiploic arteries. Arch Int Pharmacodyn Ther 1992;320:56-67.

14. Buikema H, Grandjean JG, van der Broek S, van Gilst WH, Lie $\mathrm{KI}$, Wesseling $\mathrm{H}$. Differences in vasomotor control between 
human gastroepiploic and left internal mammary artery. Circulation 1992;86(Suppl):II-205-9.

15. Kannel WB. Risk factors for atherosclerotic cardiovascular outcomes in different arterial territories. J Cardiovasc Risk 1994;1:333-9.

16. Tanaka T, Fujita M, Fudo T, Iwase T, Tamaki S, Nohara R, et al. Responses of internal mammary artery to local administration of acetylcholine. Am J Cardiol 1996;77:302-4.

17. Berkenboom G, Crasset V, Giot C, Unger P, Vachiery JL, LeClerc $\mathrm{JL}$. Endothelial function of internal mammary artery in patients with coronary artery disease and in cardiac transplant recipients. Am Heart J 1998;35:488-94.

18. Voors AA, Oosterga M, Buikema H, May JF, Grandjean JG, van Buiten A, et al. Dyslipidemia and endothelium-dependent relaxation in internal mammary arteries used for coronary bypass surgery. Cardiovasc Res 1997;34:568-74.

19. Hanet C, Robert A, Wijns W. Vasomotor response to ergometrine and nitrates of saphenous vein grafts, internal mammary artery grafts, and grafted coronary arteries late after surgery. Circulation 1992;86(Suppl):II-210-6.

20. Gurné O, Chenu P, Polidori C, Louagie Y, Buche M, Haxhe JP, et al. Functional evaluation of internal mammary artery bypass grafts in the early and late postoperative periods. J Am Coll Cardiol 1995;25:1120-8.

21. van der Meulen J, van Son JA, van Asten WN, Skotnicki SH, Lacquet LK. Intraoperative Doppler spectrum analysis of blood flow in the internal mammary artery used for myocardial revascularization. J Thorac Cardiovasc Surg 1991; 39:281-3.

22. Werner GS, Wiegand V, Kreuzer H. Effect of acetylcholine on arterial and venous grafts and coronary arteries in patients with coronary artery disease. Eur Heart J 1990;11:127-37.

23. Hartmann A, Lahoda T, Burger W, Beyersdorf F, Schräder R, Satter P. Endothelium-dependent and endothelium-independent flow regulation in coronary vascular regions supplied by arterial and venous bypass grafts. Cardiology 1997;88:425-32.

\section{Availability of Journal back issues}

As a service to our subscribers, copies of back issues of The Journal of Thoracic and Cardiovascular Surgery for the preceding 5 years are maintained and are available for purchase from Mosby until inventory is depleted. The following quantity discounts are available: $25 \%$ off on quantities of 12 to 23, and one third off on quantities of 24 or more. Please write to Mosby, Subscription Customer Service, 6277 Sea Harbor Dr, Orlando, FL 32877, or call 800-654-2452 or 407-345-4000 for information on availability of particular issues and prices. If unavailable from the publisher, photocopies of complete issues may be purchased from Bell \& Howell Information and Learning, 300 N Zeeb Rd, Ann Arbor, MI 48106-1346; 734-761-4700 or 800-521-0600. 